\title{
BEATRIZ MAGALONI*
}

\section{La desobediencia civil en la democracia constitucional}

\section{Concepto de desobediencia civil}

Tugo Adam Bedau propone una definición "estricta" de desobeIl diencia civil que ha sido ampliaménte aceptada. Dicho autor, intentando clarificar lo que la desobediencia civil es realmente, con independencia de su justificación ética o política, sostiene que:

Alguien comete un acto de desobediencia civil, si y sólo si, sus actos son ilegales, públicos, no violentos, conscientes, realizados con la intención de frustrar leyes -al menos una-, programas o decisiones de gobiernos. ${ }^{1}$

Esta definición ha sido seguida por un gran número de autores. Así, el filósofo moral estadounidense John Rawls en su obra Teoría de la justicia sostiene siguiendo a Bedau, que la desobediencia civil es:

un acto público, no violento, consciente y político, contrario a la ley, cometido con el propósito de ocasionar un cambio en la ley o en los programas de gobierno. Actuando de este modo apelamos al sentido de justicia de la mayoría de la comunidad, y declaramos que, según nuestra opinión, los principios de la cooperación social entre personas libres e iguales, no están siendo respetados. ${ }^{2}$

* Licenciada en Derecho por el ITAM.

1 Hugo Adam Bedau, "On Civil Disobedience", en Joumal of Philosophy, No. LVIII, 1963, p. 661.

${ }^{2}$ John Rawls, Teoria de la justicia, versión castellana: María Dolores González, México, Fondo de Cultura Económica, 1978, p. 405. 
Así, para Rawls, la desobediencia civil busca inducir a un cambio en normas jurídicas o políticas gubernamentales que se consideran ilegítimas a la luz de los principios que rigen la vida social, es decir, ésta pretende identificarse con los fundamentos constitucionales del Estado democrático: asimismo, dicho cambio se logra porque a través de la protesta se apela al, sentido de justicia de la mayoría, esto es, a ciertos valores que son comúnmente compartidos por los ciudadanos. Este autor acepta, como la mayoría de los autores de la así llamada tendencia liberal, la desobediencia civil directa e indirecta. La primera consiste en la violación de una norma jurídica que en sí misma es considerada injusta; la segunda, desobedece leyes en sí mismas válidas, como las de tránsito, con el fin de protestar y plantear el propio caso cuando no hay medio de violar los programas de gobierno objetados directamente. Según este autor, la desobediencia civil es el eje central para la adecuada comprensión de los fundamentos morales de la democracia porque implica la cuestión de la naturaleza y límite de la regla de las mayorías con base en la cual se adoptan decisiones públicas obligatorias en un sistema democrático.

También Jürgen Habermas acepta la misma línea de definición de desobediencia civil. El, al referirse a la desobediencia civil, cita la definición de John Rawls y al respecto comenta:

Son irrebatibles las determinaciones fundamentales que se derivan del objetivo de la apelación a la capacidad de raciocinio y sentido de justicia de una mayoría de ciudadanos. $\mathrm{La}$ desobediencia civil es una protesta moralmente fundamentada en cuyo origen no tienen por qué encontrarse tan sólo convicciones sobre creencias privadas o intereses propios; se trata de un acto público que, por regla general, es enunciado de antemano y cuya ejecución es conocida y calculada por la policía; incluye propósito de violación de normas jurídicas concretas, sin poner en cuestión la obediencia frente al ordenamiento jurídico en su conjunto; requiere la disposición de admitir las consecuencias que acarrea la violación de la norma jurídica; la violación de la norma, que es la manifestación 
de la desobediencia civil tiene exclusivamente un carácter simbólico: aquí es donde reside el límite de los medios no violentos de protesta. ${ }^{3}$

Habermas considera que la desobediencia civil, por sus características esenciales, se desenvuelve dentro del marco constitucional del Estado democrático, en la medida en que busca configurar de una manera no convencional la voluntad política colectiva, para lo cual los desobedientes deben fundamentar su posición en argumentos que puedan ser objeto de un consenso y no en convicciones privadas del mundo, a pesar de que ambos aspectos pueden coincidir. Entonces, la desobediencia civil busca identificarse precisamente con los principios políticos comúnmente compartidos que sirven de fundamento a los Estados democráticos. Habermas muestra que esta forma de conducta cívica, a diferencia de otros actos políticamente motivados, no busca la ruptura o reorganización del orden constitucional; los actos de desobediencia civil utilizan la violación de las leyes, en forma simbólica y calculada, para comprometer la conciencia moral de toda la comunidad, forzándola a revisar una cuestión a la luz de sus fundamentos de legitimidad. Por ello, según este autor, la desobediencia civil desempeña un importante papel innovativo y correctivo en un sistema democrático y la respuesta que el Estado le dé y su capacidad de incoporarla al proceso institucional constituye la prueba de fuego de la madurez democrática que ha alcanzado.

En un sentido similar, Paul F. Power sostiene que la desobediencia civil:

Es una violación de las leyes de un sistema determinado, deliberada, pública y en forma articulada, que busca cambiar las leyes o políticas del régimen, no dañina a la integridad de la persona, que respeta los derechos de otros y que se lleva a cabo dentro de la jurisdicción del Estado para expander y aplicar la ética democrática. ${ }^{4}$

\footnotetext{
${ }^{3}$ Jürgen Habermas, Ensayos politicas, p. 56.

${ }^{4}$ Paul F. Power, "Civil Disobedience as a Functional Oposition" en The Joumal of Politics, Vol. 34, No. 1, 1972, p. 40.
} 
Así, Power entiende por desobediencia civil un método especial de oposición, que por sus características esenciales, es decir, al ser un acto público, no violento y que busca un cambio político, debe ser situado dentro de los regímenes democráticos. Más aún, la desobediencia civil, al llevarse a cabo dentro de la jurisdicción del Estado-lo que se manifiesta, en última instancia, por el sometimiento voluntario a las conseucencias legales del acto de desobedienciapara Power desempeña el papel de realizar los más altos valores de la democracia. De esta forma, muestra que la desobediencia civil, en la medida en que se coloca dentro de la jurisdicción del Estado para producir un cambio en una ley o política, no busca derrocar al gobierno o transformar la estructura social básica. Asimismo, el que la desobediencia civil deba cometerse en público y satisfacer la obligación de la no violencia, en efecto la sitúa dentro de los valores políticos fundamentales de la democracia: al cometerse en público, se busca incitar una discusión crítica de aspectos vitales para la existencia de la comunidad, y al ser no violenta, manifiesta que "las personas desobedientes respetan los derechos humanos como valores morales y el cambio pacífico como esencial al proceso democrático". 5

En el extremo opuesto a la discusión que hasta ahora se ha venido planteando, está la posición de Joseph Raz. Este autor sostiene que las definiciones llamadas "estrictas" de desobediencia civil confunden el acto político en sí mismo con las condiciones bajo las cuales la violación al derecho se considera justificada. Raz sostiene que dichas definiciones lo que en realidad hacen es "señalar una clase de acción política legitima", por lo que él busca una definición que sea "valorativamente neutra" y que separe la caracterización de este tipo de actos políticos de su justificación. ${ }^{6}$ Más aún, considera que "los análisis de la desobediencia civil que favorecen un limitado entendimiento de la expresión tienen sentido únicamente en el supuesto de que exista un derecho a la desobediencia civil ${ }^{7}{ }^{7}$ Raz afirma que en la democracias la desobediencia civil no sólo es una

5 Ibidem, p. 40.

6 Joseph Raz, La autoridad del Derecho, ensayos sobre derecho y moral versión castellana: Rolando Tamayo y Salmorán, Universidad Nacional Autónoma de México, México, 1982, p. 327.

${ }^{7}$ Ibidem. 
conducta ilícita, sino moral y políticamente reprobable, por cuanto que en estos sistemas políticos existen vías para la participación política, el control del ejercicio del poder y la reivindicación de derechos ciudadanos. Si se niega la posibilidad de que exista un derecho a la desobediencia civil como lo hace Raz, el desarrollar una teoría de la desobediencia civil dentro del marco de las democracias constitucionales no tiene sentido. Implicaría el riesgo, en palabras de Raz, de "volver rutina y una forma regular de acción política" a un acto que se "encuentra fuera de los límites legítimos de tolerancia". ${ }^{8}$ Es únicamente en el que Raz llama Estado no liberal, donde existe efectivamente un derecho a la desobediencia civil, dado que ahí se niega a los ciudadanos el derecho a la participación política.

Raz define la desobediencia civil como "una violación del derecho políticamente motivada, hecha ya sea para contribuir directamente al cambio del derecho o de una política o, bien, para expresar la protesta de uno, en contra o para disociarse de una disposición jurídica o de una política".? Una definición amplia de desobediencia civil como la propuesta por dicho autor, no explica adecuadamente el fenómeno de la desobediencia legal realizada para desconocer una ley o política gubernamental contrarias a los principios democráticos fundamentales cuando las vías institucionales de participación política y jurídica están cerradas. El que la desobediencia civil se defina como un acto público y no violento, es precisamente lo que la convierte en una vía alternativa para participar en la formación del consenso -que es la base moral de la democracia-ahí donde los cauces ordinarios de toma de decisiones se encuentran negados a los ciudadanos. Este autor en general es optimista respecto al funcionamiento de las instituciones de los Estados democráticos, por lo que no considera necesario el teorizar en torno a lo que parece presentarse como una estrategia de cambio social acorde con la democracia. No obstante, la postura de Raz plantea una importante objeción formulada con frecuencia a la desobediencia civil desde el punto de vista de la democracia. Es

${ }^{8}$ Ibidem La cursiva ha sido agregada.

${ }^{9}$ Ibidem P. 324. 
decir, cómo es posible justificar la desobediencia civil si existen vías eficientes para el intercambio del poder en un régimen democrático -aspectos que se analizan más adelante.

De esta forma, Raz, al considerar que la desobediencia civil puede ser tanto violenta como no violenta, está confundiendo este fenómeno con la violencia política. Es importante aclarar que al definir la desobediencia civil como no violenta, no está intentando, como Raz objeta, definir una forma legítima de actuar. El que los actos de desobediencia civil sean, entre otros elementos, no violentos no hace que se toleren en sí mismos, con indpendencia de sus causas y finalidades. No obstante, parece un hecho indiscutible que la no violencia es, por lo general, preferible a la violencia, dado que la primera refleja, utilizando las palabras de Karl Popper, ${ }^{10}$ "fe en la razón", mientras que con la segunda se corre siempre el riesgo, como lo afirma Hannah Arendt, ${ }^{11}$ de que "los medios sobrepasen a los fines que la justifican", volviéndose irracional.

Asimismo, cabe señalar que el hecho de que se afirme que la desobediencia civil es, entre otras cosas, no violenta, no implica que se considere que sólo esta forma de disenso se encuentra justificada en un Estado democrático. La violencia en ciertos casos extremos de injusticia puede ser un medio legítimo y necesario. Por ejemplo, cuando un grupo concentra el mando valiéndose de manipulaciones, engaños, amenazas y terror. Sin embargo, si la resistencia a la autoridad es violenta, se trata de un problema diverso al de la desobediencia civil.

Hay otros autores que, a diferencia de Raz, justifican la desobediencia civil en los sistemas democráticos, pero que no consideran que la no violencia sea uno de sus elementos esenciales. Así, por ejemplo, Howard Zinn afirma que ésta "consiste en vaciar intencional y voluntariamente una ley para realizar un propósito vital". ${ }^{12}$ Este autor considera que quienes opten por una desobediencia civil "deben seleccionar las tácticas menos violentas para hacer eficaz su protesta y significar su problematicidad", ${ }^{13}$ pero no considera que

\footnotetext{
${ }^{10}$ Karl R. Popper, Conjeturas y refutaciones, Paidós, México, 1983.

${ }^{11}$ Hannah Arendt, Sobre la violencia, versión castellana: Miguel González, Cuadernos de Joaquín Mortiz, México, 1970.

${ }^{12}$ Howard Zinn, citado por Gustavo Marrero, "Il Estado de Derecho y la desobediencia civil", en Revista de Derechos Humanos, Vol. II, No. 1, 1971, p. 39.

${ }^{13}$ Ibidem.
} 
la no violencia o la publicidad sean elementos constitutivos de la desobedencia civil. Por el contrario, considera que en la medida que con la desobediencia civil se busca llamar la atención de la comunidad sobre una determinada situación, la no violencia es una táctica racional para lograr dicho objetivo, dado que ésta será más eficaz que la violencia en atraer la opinión pública a su favor.

Aquí se toma la línea de definición estricta de desobediencia civil propuesta por Bedau. Como se ha dicho, establecer la diferencia crucial entre la desobediencia civil y la violencia política, permite valorar a la primera como una estrategia de transformación social acorde con los fundamentos de las democracias constitucionales. El llamado movimiento de los derechos civiles, precedido por Martin Luther King en los Estados Unidos, precisamente demostró que la desobediencia civil puede ser una forma legítima de resistencia en un Estado democrático. Dirigido a cuestionar situaciones bien determinadas de injusticia bajo los principios constitucionales y no a fracturar la legitimidad del ordenamiento jurídico en su conjunto o a tomar el poder político, el movimiento de los negros no podía ser equiparado con la violencia política, la anarquía o el crimen. Este movimiento de desobediencia civil planteó un nuevo reto moral y político a la democracia norteamericana, y la conceptualización de Bedau es la que mejor permite visualizarlos. En la medida en que la resistencia se manifestó en forma pública, no violenta y sobre el fundamento de consideraciones político-morales, estaba dirigida a instituciones capaces de integrar la crítica, autocorregirse y reformarse pacíficamente.

\section{Desobediencia civil y Democracia constitucional}

La reflexión de la desobediencia civil en un sistema político como el democrático, debe necesariamente partir del hecho de que ésta es una actividad ilegal porque viola normas jurídicas válidas y vigentes -aunque éstas puedan ser moral y jurídicamente reprobables- que se comete con el fin de producir un cambio. En este sentido, la desobediencia civil no sólo viola normas jurídicas, sino que sobrepasa aquellos canales ordinarios, tanto jurídicos como 
políticos, que en un sistema democrático existen para la producción del cambio de leyes o políticas gubernamentales, es decir, se coloca fuera de las reglas del juego que sustentan a este sistema político.

La desobediencia civil, desde un punto de vista puramente jurídico formal, sólo puede ser considerada como un acto ilegal, aunque no necesariamente delictivo. En esta medida el significado de esta forma de conducta cívica debe buscarse en un espacio metajurídico, que precisamente lo constituyen aquellas concepciones políticomorales que sustentan a las instituciones democráticas.

El hecho de que para algunos autores la desobediencia civil atente en contra de la democracia misma, mientras que para otros desempeñe un importante papel innovativo y correctivo y pertenezca esencialmente a este sistema político, se explica en la medida en que dichas posturas corresponden a dos nociones de democracia. La primera es la noción de democracia formal que refleja una preocupación por la validez de los procedimientos democráticos. La segunda es la noción de democracia sustantiva que se preocupa porque los resultados del proceso democrático correspondan con principios político-morales aceptables.

\section{Noción formal de democracia}

Para quienes sostiènen uná noción puramente procedimental de la democracia, el fundamento de legitimidad y de obligatoriedad de las leyes y políticas gubernamentales está, precisamente, en el hecho de que hayan sido formuladas conforme a los procedimientos democráticos, en cuanto que éstos son los medios más eficaces de garantizar la obtención de resultados legítimos y vías eficientes para la participación política y el control del ejercicio del poder.

Una noción formal de democracia se caracteriza entonces, por validar a la democracia por sus reglas procesales. Bajo este punto de vista, la dewrocracia se concibe como un conjunto de reglas para la constitución del gobierno y para la formación de las decisiones públicas vinculantes para toda la comunidad. Entonces, dichas relgas establecen quién está fácultado para tomar las dècisiones y bajo qué procedimientos, es decir, la manera como se debe llegar a una decisión política obligatoria, pero no qué se debe decidir. Por 
lo tanto, el hecho de que dichas decisiones se tomen conforme al procedimiento prescrito constituye el único criterio para determinar su validez. Entre estas reglas del juego, también llamadas "de procedimientos universales", se pueden distinguir, utilizando la enumeración de Bobbio, ${ }^{14}$ las siguientes:

1. El poder legislativo es el supremo poder político y debe estar compuesto por miembros elegidos directa o indirectamente por el pueblo.

2. Los entes administrativos o jefe de Estado deben también ser elegidos y actuar junto al supremo órgano legislativo.

3. Los electores deben ser todos los ciudadanos, sin ninguna clase de distinción por razón de raza, religión, ingresos y sexo, que hayan alcanzado la mayoría de edad.

4. Todos los votos tienen igual valor y cada elector tiene derecho a un voto.

5. El voto debe ser libre, según la propia opinión del elector y representar la elección entre alternativas reales.

6. Las elecciones de los representantes y las decisiones del supremo órgano político se toman con base en la regla de las mayorias.

7. La mayoría no puede limitar los derechos de la minoría, especialmente el derecho de volverse mayoría.

El hecho de que en aquellas sociedades contemporáneas en las que los procedimientos democráticos se siguen con un alto grado de fidelidad, se presenten diversos movimientos de desobediencia civil, cuyas manifestaciones más obvias son el movimiento por la paz, el movimiento por el medio ambiente y diversos movimientos cen-

\footnotetext{
${ }^{14}$ Norberto Bobbio, Democracia", en Diccionario de polfica, Siglo Veintiuno Editores, Mexico, 1988.
} 
trados alrededor de los derechos humanos de minorías (presos, inquilinos, mujeres, etcếtera), cuestiona el mecanismo democrático a pesar de su pureza procedimental. Es decir, en la democracia, por un lado, se pueden generar políticas que los ciudadanos perciben como ilegítimas aunque legalmente no se haya violado ningún procedimiento; y por el otro, los canales políticos ordinarios como el voto o el diseño legal pueden resultar ineficaces para producir un cambio.

A pesar de que formalmente se le dé un voto a cada individuo, esto no es garantía de que de hecho se tenga capacidad de incidir en las decisiones colectivas, existen otros factores determinantes que hacen que el derecho "universal" a la participación política no sea de hecho igualitario. Factores como la desigualdad económica y el hecho de que se financien con fondos privados las elecciones y los partidos políticos y que se puedan controlar con poder económico los medios masivos de comunicación, hace que en el foro político prevalezcan los intereses de los grupos dominantes. Así, los problemas de legitimidad en la actualidad, según lo señala Habermas, no pueden desligarse de los problemas de desigualdad de diversa indole. $^{15}$

De esta manera, no obstante que la representación política formalmente sea un llamado para velar por los intereses de la nación y en este sentido contrario al principio del mandato imperativo, de hecho se convierte en representación de intereses, con lo que disminuye la posibilidad de que se tomen decisiones imparciales.

También en esta línea de argumentación, a pesar de que formalmente existan opciones, es decir, dos o más partidos políticos compitiendo por la representación nacional, éstas no necesariamente representan opciones reales, en el sentido de constituir medios para promover la realización de los intereses sociales. Claus Offe ${ }^{16}$ ha señalado que el modelo de competencia electoral de partidos y la negociación colectiva institucionalizada, como formas de organización burocrática de la participación política, transforman y distorsionan la voluntad popular por tres razones. En primer lugar,

\footnotetext{
${ }^{15}$ Jürgen Habermas, Problemas de legitimación en el capitalismo tardio, versión Castellana: José Luis Etcheverry, Amorrortu Editores, Buenos Aires, 1975.

${ }_{16}$ Claus Offe, "Las contradicciones de la democracia capitalista", en Cuadernos Politicos, No. 24, 1982.
} 
porque los partidos políticos, para triunfar en el mercado político y conservar alianzas", tienden a desradicalizar la ideología del partido y minimizar aquellos elementos que puedan crear antagonismos en el electorado. En segundo término, los imperativos de la competencia hacen que el partido se convierta en una organización sumamente centralizada y burocratizada, lo que hace que predomine el personal administrativo por sobre los miembros de la base. En tercer lugar, el hecho de que el partido busque "captarlo todo" hace que se disuelva la identidad colectiva de los miembros del partido y por lo tanto, los valores político-morales compartidos. De esta manera, la vía de participación política a través de los partidos implica un sacrificio importante de individualidad y de ideales por la tendencia creciente de representar su propia maquinaria. Según dicho autor, una de las causas de la desobediencia civil, como movimiento social alternativo de organización y acción política, es precisamente esta deficiencia del sistema de partidos. Offe identifica como un elemento esencial para que la desobediencia civil se justifique en estas situaciones el hecho de que los intereses de estos grupos sociales, unidos por un fuerte sentido de identidad colectiva, no estén dirigidas hacia la toma del poder estatal, sino a defender cierto territorio moral o promover la realización de valoreś.

Aunque formalmente se faculta a la autoridad con un poder discresional circunscrito a ciertos parámetros, de hecho el poder discresional se convierte en poder arbitrario cuando los parámetros no están bien definidos o cuando la complejidad de la realidad los sobrepasa. Grandes decisiones políticas se toman fuera del proceso democrático, sin darles publicidad y por un pequeño grupo de tecnócratas. Son áreas que requieren de una alta especialización científica y tecnológica, en las que el poder ejecutivo tiene un alto margen de discresionalidad y respecto de las que el poder legislativo y la población en general no tienen control. Así, por ejemplo, en lo que respecta a la política nuclear, tanto militar como pacífica, y a la política ecologica, la democracia se ve trastocada, no por una violación efectiva de las reglas del juego por parte de los gobernantes, sino porque estas decisiones se encuentran en definitiva fuera del control civil democrático. Richard Falk ${ }^{17}$ señala con gran visión

\footnotetext{
17 Richand Falk, "Las armas nucleares y el fin de la democracia", en Los límites de la democracia, Vol. 2, Consejo Latinoamericano de Ciencias Sociales, Buenos Aires, 1983.
} 
la manera como la existencia de las armas nucleares altera significativamente las relaciones entre el gobierno y los ciudadanos e interfiere de manera fundamental con la democracia. Parece que en estas cuestiones vitales, se ha delegado toda la autoridad nuclear a un grupo reducido y a menudo oculto de "expertos" y a los líderes de otros Estados, quienes parecen estar tentados a tomar determinaciones no sólo sin el consentimiento popular, sino incluso en contra de éste. Aquí la desobediencia civil aparece como un instrumento de expresión democrática y reclamo legítimo de participación política, por parte de los ciudadanos que se ven excluidos, inevitable y permanentemente, de las determinaciones que definen el destino de sus sociedades.

Los cambios de gobierno en un régimen democrático no ocurren en un intervalo breve de tiempo, sino que normalmente se extienden por períodos que superan el tiempo razonable para que una mala política surta su efecto. Por esta razón, la urnas son importantes para poner fin inmediato a una decisión política considerada ilegítima (por ejemplo, la apertura de una planta nucleoeléctrica en relación a lo cual se ha presentado también la desobediencia civil), con lo que no hay manera de controlar, sin tener que agotar el proceso electoral, las políticas cotidianas del gobierno que afectan negativamente a una buena parte de la sociedad. Así, la lentitud en los cambios de gobierno, aunque presente ventajas incuestionables, sin que existan otros mecanismos alternativos de control, como el referéndum por ejemplo, plantea un conflicto entre dos tiempos. Primero, el de la instrumentación de una política no deseada; segundo, el del tiempo que se requiere por la vía institucional electoral para desarticular la política en cuestión.

En suma, en la democracia, aun cuando el procedimiento sea efectivamente observado, a menudo hay elementos económicos políticos y sociales que inciden indirectamente para producir resultados incorrectos y hacen que las condiciones para una decisión pública o norma jurídica legítimas sean tan sólo formalmente presentadas. La experiencia histórica demuestra que la legitimidad no queda satisfecha sólo por el hecho de que las leyes, políticas o medidas se dicten conforme al procedimiento prescrito. Así, la mayoría de los movimientos de desobedencia civil que se han presentado en las sociedades democráticas contemporáneas aparecen 
en cierta manera vinculados, no con violaciones efectivas de las reglas del juego, sino precisamente con las "fallas" anteriormente señaladas. La imperfección de la regla de las mayorías, la desigualdad efectiva del voto por la persistencia de oligarquías en el poder, la falta de una real representatividad especialmente cuando se trata de valores morales, la aparición de una tecnocracia no controlable a través del procedimiento democrático y la lentitud de respuesta de las urnas, son razones prácticas para no aceptar una noción puramente procedimental de democracia.

Adoptando la conocida distinción de John Rawls, se puede entonces afirmar que la democracia no constituye un caso de justicia puramente procesal, esto es, en el que la justicia de los resultaos se establece sólo por el procedimiento, sino más bien, un caso de justicia procesal imperfecta en el que hay criterios independientes para estimar la justicia de los resultados, y por lo tanto, el valor del procedimiento sólo está dado por su capacidad para producir resultados probablemente justos.

La democracia es evidente que no constituye un caso de justicia procesal pura. Lo que es más, la justicia procesal pura es aparentemente aplicable sólo a los juegos de azar. Rawls señala que en los juegos de azar, como la ruleta por ejemplo, en los que las apuestas se realizan voluntariamente y bajo condiciones imparciales, el único criterio para determinar la justicia del resultado lo constituye el propio procedimiento. Así, si éste es imparcial y efectivamente observado, el resultado es correcto. Pero la democracia no puede asemejarse a un juego de azar, especialmente si se considera el tipo de cuestiones fundamentales que se deciden a través de sus procedimientos.

La democracia parece más cercana al modelo de justicia procesal imperfecta. Ésta, según Rawls, se caracteriza por ser muy similar a los procesos judiciales. Lo importante de un proceso judicial es que su imparcialidad depende, en gran medida, de la fidelidad con que se sigan una serie de pasos ya establecidos. Es decir, el resultado de un juicio es probablemente justo porque reduce al mínimo la subjetividad que puede llevar a arbitrariedades, ya que resuelve conforme a criterios generales. Sin embargo, esto no siempre es así. 
Se puede, por ejemplo, condenar a alguien que es inocente cuando la complejidad de la realidad sobrepasa lo que ha sido previsto por las leyes.

Lo mismo sucede con la democracia. El proceso democrático no asegura necesariamente un resultado democrático. Por ello, se deben aclarar las razones por las que los procedimientos democráticos tienden a producir resultados justos, aunque no los aseguren y sobre todo, precisar qué tipo de criterios independientes sirven para evaluar la justicia de dichos resultados. Consecuentemente, hay que examinar una noción sustantiva de democracia.

\section{Noción sustantiva de democracia}

Una noción sustantiva de democracia distingue entre las reglas procesales y los resultados que se producen.

Las reglas procesales de la democracia tienden a producir resultados justos porque se asemejan, en términos de Habermas, a un proceso de formación racional de la voluntad. No sólo esto, sino que dan un clima de seguridad jurídica que permite, en última instancia, que la sociedad sea viable. La idea de formación racional de la voluntad implica tomar como punto de partida que en toda sociedad existen conflictos de intereses y que cada individuo, portador de dichos intereses, tiene una voluntad autónoma, libre e inviolable. No obstante esta diversidad, se puede llegar a un acuerdo, es decir a una formación de voluntad, sobre ciertos principios normativos generales dignos de ser reconocidos por cada individuo por ser consecuente con sus intuiciones y convicciones respecto a lo que es justo. Esto se logra, cuando existe un diálogo racional, que parta de la tolerancia y que garantice la imparcialidad.

Así, los procedimientos tienden a hacer de la democracia un sistema abierto y respetuoso del disenso; sujeto a una vigilancia y revisión continuas y encaminado a renovarse permanentemente a través del libre debate de las ideas; la tolerancia y la no violencia la convierten en el único sistema político que idealmente permite la elección, experimentación y crítica de distintas alternativas de sociedad, la discusión racional de los asuntos públicos y la autocorrección de las desviaciones y abusos del poder. Como bien ha señalado 
H.A.L. Hart, ${ }^{18}$ una de las grandes justificaciones de la democracia es que permite la experimentación y una elección revisable entre distintas alternativas. Por estas razones se acepta el procedimiento democrático, porque busca producir resultados correctos, aunque lo logre en forma imperfecta.

El hecho de que los procedimientos democráticos tiendan a producir resultados justos, revela que una buena parte de la legitimidad de las decisiones políticas en la democracia se da cuando se dictan conforme a dichos procedimientos. Por ello cabe hablar, siguiendo a Habermas, no sólo de legalidad procedimental sino de legitimidad procedimental. La manifestación más clara de esto lo constituye la presunción, por parte del ordenamientojurídico, de que toda acción conforme al derecho es legítima. Es decir, el Derecho descansa sobre la suposición de que el poder es legítimo cuando respeta la legalidad y se ejerce con base, no en el propio capricho, sino en los límites impuestos por las leyes preestablecidas. Esto se puede ver con toda claridad en los procesos judiciales; si las sentencias son producto de un procedimiento seguido con fidelidad, que garantice de manera imparcial la defensa de las partes, y no son apeladas dentro de los plazos establecidos, se consideran válidas e irrevocables.

Sin embargo, las políticas elegidas democráticamente no necesariamente son "buenas" o "legitimas". Estas pueden ser moralmente reprobables, como por ejemplo, las que implican oprimir a una minoría (tal como ocurrió con las leyes racistas norteamericanas), declarar guerras injustas o perseguir a los "herejes". Es por ello, que autores como Habermas y Bobbio, han sugerido la necesidad de que dichas reglas cumplan con ciertos presupuestos mínimos si se quiere que conserven su poder de legitimación que, como se ha visto, a menudo es imperfecto.

Muchos Estados democráticos padecen de un culto a los procedimientos, esto es, intentan fundamentar la legitimidad de sus decisiones políticas sólo en el hecho de que formalmente al dictarlas se respeten las reglas del juego. El cumplimiento simbólico de los

\footnotetext{
${ }^{18}$ H.A.L. Hart, citado por Eusebio Fernández, Teorla de la justicia y Derechos Humanos, Editorial Debate, Madrid, 1984.
} 
procedimientos puede ser utilizado como una forma de ocultamiento para evitar entrar a discutir las implicaciones morales que toda decisión política tiene, especialmente las fundamentales.

Como afirma Habermas:

En cuestiones fundamentales no es suficiente la legitimidad procedimental: el propio procedimiento y la totalidad del ordenamiento jurídico han de poder justificarse fundamentándose en principios. Estos fundamentos que legitiman a la propia Constitución han de contar con reconocimiento por los demás con indpendencia de que el derecho positivo coincida con ellos o no. ${ }^{19}$

De esta manera, no basta con que una norma jurídica o una decisión pública se adopte conforme al procedimiento democrático; es necesario, además, que ésta sea consecuente con los supuestos normativos que legitiman al propio Estado democrático constitucional.

Los presupuestos mínimos frente a los que en última intancia se debe validar una decisión democrática son aquellos principios constitucionales valiosos en sí mismos y que merecen una aceptación reflexiva y voluntaria, como por ejemplo, el reconocimiento constitucional de los derechos humanos inviolables, la soberanía popular, el consenso ciudadano, la seguridad jurídica, el debido proceso legal, la igualdad ante la ley, los principios del Estado social, etcétera. Para Habermas:

Todas ellas siguen una intuición de que únicamente pueden justificarse aquellas normas que expresan un interés suceptible de ser generalizado y que, en consecuencia, contaría con la aprobación voluntaria de todos los afectados. ${ }^{20}$

La necesidad de que las decisiones políticas se validen a la luz de los principios constitucionales fundamentales se hace patente con la existencia de medios institucionales de control de constituciona-

19 Jürgen Habermas, Ensayas polticos, p. 83.

${ }^{20}$ Ibidem, p. 59. 
lidad. La revisión judicial es precisamente el mecanismo ideado para este fin. Los tribunales están facultados para decidir si una norma jurídica emanada del poder legislativo, una sentencia judicial o un acto del ejecutivo, satisfacen o no los principios constitucionales, con independencia de que se hayan adoptado conforme a los procedimientos.

En consecuencia, la democracia formal precisa continuamente de mecanismos de revisión y autocorrección a la luz de principios. Éstos, sin embargo, también fallan. El control jurisdiccional se enfrenta con importantes limitantes, especialmente de naturaleza política que, sobre todo en cuestiones fundamentales, lo convierten en un mecanismo limitado de control de constitucionalidad. Por un lado, existen importantes problemas políticos que involucran violaciones a los principios de moralidad pública respecto de los que los procesos judiciales son improcedentes. Así, por ejemplo, la negativa de los tribunales para juzgar respecto de la constitucionalidad de los actos del Ejecutivo norteamericano relativos a la guerra de Vietnam, en la que se negó jurisdicción con base en la llamada doctrina de la cuestión política, llevó a un gran número de ciudadanos a colocarse fuera de las reglas del juego para manifestar su inconformidad. Lo mismo ha ocurrido con el movimiento de desobediencia civil en contra de la apertura de la planta nucleoeléctrica de Laguna Verde en México. Al respecto, los juzgados administrativos competentes declararon la improcedencia de las numerosas demandas de amparo presentadas, por considerar, acertadamente en términos jurídicos, que "los actos de afectación a la vida y a la salud son inciertos", lo que constituye una causal de improcedencia del Juicio de Amparo. Por otro lado, a menudo las sentencias judiciales son impotentes para transformar de hecho realidades complejas. Patrones socio-culturales y formas tradicionales de conducta de la autoridad, tal como ocurrió, por ejemplo, en relación a las sentencias de los tribunales federales en Estados Unidos que, a pesar de que declaraban inconstitucionales las leyes racistas de los estados del sur, no se tradujeron en la abolición del racismo como sistema de vida. Esto demostró las limitaciones de la revisión judicial para transformar ciertas instituciones políticas y estructuras socio-cultu- 
rales. Por último, los tribunales no están siempre inmunizados de las influencias políticas, que pueden ocasionar decisiones que se perciben como ilegítimas.

De esta manera, se puede presentar una doble falla en la democracia constitucional. En primer lugar, aún cuando los procedimientos se sigan fielmente, se pueden generar decisiones políticas que se perciban como ilegítimas; en segundo término, los mecanismos institucionales de control pueden resultar limitados por ser improcedentes, por tener alcances muy reducidos o por generar sentencias equivocadas. Frente a estos hechos, la desobediencia civil puede ser el único recurso disponible para ocasionar la revisión de una decisión política que se perciba como ilegítima.

Detrás de las formas procesales y de las Constituciones democráticas hay ciertos presupuestos necesarios o principios normativos político-morales que les dan su razón de ser y conforme a las que ha de justificarse, en última instancia, la desobediencia civil. Sólo partiendo de este hecho es comprensible porqué para Habermas el problema de la desobediencia civil en el Estado democrático constitucional únicamente puede surgir si se parte del supuesto de que éste precisa de una justificación moral y al mismo tiempo es capaz de ella.

Así, la principal fuente de justificación de la desobediencia civil en un sistema democrático, la constituyen los principios legitimantes del Estado constitucional, cualquiera sea la teoría moral que sirva para fundamentarlos. En consecuencia, la desobediencia civil se justifica en la democracia cuando se generan normas jurídicas o decisiones políticas ilegítimas porque son contrarias, no a una moral privada, sino precisamente a dichos principios político-morales y no hay otro recurso institucional disponible. Es por esto que resulta esencial distinguir a la desobediencia civil de la objeción de conciencia. Sobre todo en tanto que la desobediencia civil, en la medida en que busca un cambio con efectos generales, apela necesariamente a principios político-morales aceptados en la sociedad; mientras que la segunda, al buscar inmunidad personal respecto de determinada ley o mandato de autoridad, se funda en principios morales o religiosos individuales, que incluso pueden estar en contra de los de la sociedad. 
La desobediencia civil obliga a que toda decisión democrática se mire a la luz de estos principios legitimantes lo cual moraliza el quehacer político. Exige que éstas se justifiquen, no sólo por haber sido dictadas por el voto mayoritario, sino porque sean consecuentes con los principios político-morales que sustentan al Estado y a la comunidad social. En este momento se vuelve un problema que implica a toda la sociedad, que un régimen que se dice igualitario sancione leyes racistas o que un gobierno que se responsabiliza de la conservación ecológica permita que se exploten irracionalmente los recursos naturales. La desobediencia civil parece ser de las pocas vías que permiten que se dé esta moralización, especialmente si se toma en cuenta que los partidos políticos evitan hacer suyas demandas con fuertes contenidos morales, lo cual ha cerrado las vías institucionales de crítica y disenso. Se convierte entonces, en una vía no convencional de formación racional de la voluntad política: la desobediencia civil apela a la capacidad de razonar y a la conciencia moral de la sociedad para suscitar un nuevo debate, por un procedimiento distinto, respecto de una política gubernamental considerada ilegítima.

De esta manera, la desobediencia civil, en su carácter de disenso no institucional, tiende a la consolidación de un consenso, que es la base moral de la democracia. En un régimen democrático, para que exista un consenso de la mayoría, es necesario que exista una minoría que disiente. Por ello en la democracia la regla de mayorías debe necesariamente cumplir, siguiendo a Habermas, con que ninguna decisión tomada por la mayoría pueda limitar los derechos de la minoría, que no puede haber minoría alguna por nacimiento y que la mayoría no pueda tomar decisiones irreversibles. Como bien lo explica Bobbio, el consenso no organizado, manipulado o impuesto desde arriba supone el disenso, porque "solamente ahí donde el disenso es libre de manifestarse, el consenso es real y solamente ahí donde el consenso es real, el sistema puede llamarse justamente democráticon. ${ }^{21}$ De esta manera, existe una relación indiscutible entre democracia y disenso. Bobbio señala que las instituciones democráticas reconocen canales legales a través de los que se puede

${ }^{21}$ Norberto Bobbio, El futuro de la democracia, p. 49. 
manifestar el disenso sin que sea destructivo para el sistema político, tales como la libertad de opinión, de prensa, de manifestación y de formar partidos políticos.

La desobediencia civil, a diferencia del disenso legal, se coloca fuera de los canales ordinarios, pero precisamente cuando éstos han demostrado ser ineficaces para producir un cambio o dar un espacio para generar un debate público sobre la legitimidad de una política. No obstante, no busca ser un acto destructivo del sistema político sino innovativo. Es decir, la desobediencia civil, a pesar de ser una actividad ilegal, por el tipo de consideraciones político-morales que la acompañan y los medios que utiliza, se diferencia esencialmente, como se ha analizado, de otros actos destructivos del sistema político, como por ejemplo, la conducta delictiva o revolucionaria.

En esta medida, puede ser en efecto, una vía de participación en la formación del consenso, en aquellas cuestiones fundamentales respecto de las que las vías institucionales están cerradas, que pertenece esencialmente a la democracia. Esta no es un estado estático y tampoco una construcción acabada. Es por el contrario, un sistema encaminado a revisarse, autocorregirse y reformarse de una manera permanente, pacífica y gradual. Junto con las formas legales de la democracia como la elecciones, los debates parlamentarios, la división de poderes y la revisión judicial, la desobediencia civil, aunque sea por definición una actividad ilegal, puede ser un vigilante no institucional de legitimidad y un motor de cambios no violentos, precisamente porque apela a los principios políticos fundamentales y busca ser incorporada, por los medios que utiliza, a los procesos institucionales. Así, el hecho de que sea una actividad pública, no violenta, conciente, utilizada como último recurso y con la disposición a aceptar, la sanción legal, posibilita que la desobediencia civil pueda, en efecto, ser incorporada por un sistema democrático abierto a pesar de ser ilegal.

Es por esto que, como afirma Habermas, la prueba de fuego de la madurez democrática de un Estado está precisamente en el tipo de respuestas que le dé a la desobediencia civil. El disenso puede aparentar moverse en tres niveles, aunque cada uno se funda en motivos radicalmente distintos. El nivel en el que éste se manifieste con frecuencia depende de la mayor o menor apertura de los canales institucionales y de la respuesta estatal. 
El primer nivel lo constituye el disenso legal, el único que se manifiesta por los canales institucionales ordinarios. El segundo nivel lo constituye la desobediencia civil, que implica una violación de normas jurídicas o mandatos de autoridad, pero que se realiza dentro de la jurisdicción del Estado, lo que se manifiesta, entre otros hechos, por ser un acto público, no violento, realizado previo agotamiento de los recursos ordinarios y manifestando la aceptación voluntaria de las consecuencias legales, en el sentido de que no responde con violencia al arresto ni se evade de la fuerza pública. El último nivel lo constituyen los delitos políticos, que implican no sólo colocarse fuera de las reglas del juego, sino utilizar otros elementos de coerción que el Estado califica como delictivos, como la violencia, con el fin de asumir el poder y lograr ciertos objetivos ideológicos, pero fuera de las estructuras existentes.

A pesar de que estas formas de disenso difieran esencialmente, el Estado, según la respuesta que les dé, puede fácilmente hacerlas parecer iguales. Así, un Estado cerrado, que base su existencia principalmente en las leyes penales, tenderá a ser intolerante y a convertir el disenso legal en ilegal y éste en delincuencia política. En cambio, un Estado abierto, que se caracteriza por poder albergar un mayor grado de disenso, puede no sólo tolerar a la desobediencia civil sin desmoronarse, sino incorporarla al proceso institucional.

Precisamente esta diferencia marca porqué la desobediencia civil es muy riesgosa, tanto para quien la comete como para el Estado mismo. Por un lado, los desobedientes civiles siempre corren peligro porque no saben de antemano qué tan maduro es el sistema político y en consecuencia no pueden prever cuál será la respuesta estatal; por el otro, el Estado no sabe cuál es su grado de madurez y hasta dónde puede sacrificar cierta seguridad jurídica sin poner en juego su existenica. La siguiente sección explora este dilema en la democracia.

\section{¿Seguridad jurídica o legitimidad?}

La desobediencia civil, en tanto que viola leyes estatales, atenta en contra de la seguridad jurídica. Al mismo tiempo, la desobediencia civil es un acto dirigido a cambiar, revisar y criticar una decisión 
política que se considera ilegítima y en este sentido protege la legitimidad del sistema político. En consecuencia, obliga a la democracia a optar, aunque sólo sea momentáneamente, entre dos valores: seguridad jurídica o legitimidad.

La opción sin embargo no es sencilla porque, como Habermas afirma, ambos valores son base de la existencia del Estado democrático en igual medida.

La seguridad jurídica es uno de los bienes más preciados que el Estado garantiza. En alguna medida, una de las principales justificaciones de la existencia del Estado ha sido precisamente que, mediante el monopolio de la violencia, asegura la existencia de la sociedad y la paz interior. No sólo esto, sino que la observancia general de las normas jurídicas y mandatos de autoridad permite que los individuos se muevan dentro de un marco legal con igual libertad y autonomía y que realicen sus planes de vida. De ahí la pretensión de obligatoriedad inexorable que caracteriza a un ordenamiento jurídico.

La legitimidad es la mayor aspiración de un Estado democrático que pretende que los ciudadanos acepten voluntariamente y por convicción el orden político y jurídico. Para Habermas, dicha aceptación voluntaria sólo puede darse si el ordenamiento jurídico se basa en principios dignos de ser reconocidos y que expresen un interés susceptible de ser generalizado, es decir, en principios generadores de consenso. De ahí que la legitimidad aparezca "casi" como sinónimo de justicia y bien común, que junto con la seguridad jurídica, son los tres grandes valores del Derecho. Si esto es cierto, su observancia se da en forma voluntaria, y no sólo por temor a la pena, lo que asegura la estabilidad social. En palabras de Bobbio, sólo la legitimidad "hace del poder de mandar un derecho y de la obediencia un deber, es decir, transforma una relación de mera fuerza en una relación jurídica". 22

De esta manera, tanto la garantía de seguridad jurídica como la legitimidad de un orden político son condiciones indispensables para la existencia del Estado. La desobediencia civil guarda una relación tensa con ambos valores.

\footnotetext{
${ }^{22}$ Norberto Bobbio, "El poder y el Derecho", en El origen y fundamentas del pader politico, versión castellana: José Fernández Santillán, Colección enlace Grijalbo, México, 1984, p. 29.
} 
Un movimiento de desobediencia civil surge por una crisis parcial de legitimidad, es decir, por un lado, hay la percepción de que alguna ley o política determinada es ilegítima desde el punto de vista de los principios consensuales, y por el otro, de que están cerradas las vías institucionales de disenso. Frente a estos hechos, la desobediencia civil representa el último recurso disponible para buscar producir un cambio, que a pesar de que se desenvuelve al margen del marco legal, no busca atentar en contra de éste. Por el contrario, busca ser incorporada al proceso institucional y por ello, para ser eficaz, es necesario que no se perciba por el sistema político como una amenaza. Así, las violaciones de la ley, que se realizan con el fin de apelar a la conciencia moral de la sociedad y consolidar un nuevo consenso a la luz de los principios políticos fundamentales, son simbólicas y calculadas; al ser públicas, no violentas y con la aceptación de la sanción legal, manifiestan, por usar una expresión de Rawls, fidelidad a la ley, a pesar de colocarse al margen de ésta. De esta manera, el objetivo de la desobediencia civil es precisamente restaurar esa pérdida parcial de legitimidad, lo que indirectamente ayuda a mantener la estabilidad del sistema constitucional.

Sin embargo, en el tiempo en el que se desenvuelve un movimiento de desobediencia civil, se está arriesgando, momentáneamente, seguridad jurídica porque actúa al margen de la legalidad. La desobediencia civil no sólo afecta a la seguridad jurídica por el hecho de violar leyes, sino porque sobrepasa los canales ordinarios, tanto jurídicos como políticos, que en un sistema democrático existen para producir un cambio, revisar las desviaciones y controlar el ejercicio del poder. Es decir, rebasa a la revisión judicial, a la asamblea legislativa, a los mecanismos de pesos y contrapesos y a otras formas de control institucional, que no son otra cosa que los rasgos distintivos de la democracia formal. En este sentido, se opone a la interpretación institucional respecto de los principios políticos fundamentales y su aplicación a problemas sociales concretos. Quien desobedece civilmente asume dicha competencia interpretativa y decide, con base en su propia sensibilidad moral y capacidad de raciocinio, que los principios constitucionales legitimantes no están siendo respetados. $\mathrm{El}$ hecho de que las personas decidan por sí mismas crea un clima de inseguridad jurídica. 
No obstante, por ello no se puede válidamente rechazar la desobediencia civil. En un Estado democrático, como Rawls afirma, no hay una interpretación política o socialmente aprobada de dichos principios, aun cuando provenga de un tribunal superior o de la asamblea legislativa. Más aún, su propio ordenamiento jurídico se funda en la pretensión de ser aceptado voluntariamente y por convicción por los ciudadanos. La ausencia de una autoridad final que decida no origina confusión, sino que es condición necesaria para la consolidación de un consenso reflexivo y para el avance social. En la democracia, "el último tribunal de apelación lo constituye, no un tribunal, ni el ejecutivo, ni la asamblea legislativa; sino el electorado en su totalidad" ${ }^{23}$ La desobediencia civil apela precisamente a este último y a los principios políticos que sustentan a la sociedad, por lo que una acción que en principio parece destructiva de la democracia puede, posteriormente, convertirse en consolidadora de consenso.

Por lo tanto, mientras se da el movimiento de desobediencia civil, hay un equilibrio frágil acompañado de una tensión potencialmente explosiva que caracteriza a todo momento de transición. Por un lado, el costo de recurrir a la desobediencia civil para consolidar la legitimidad puede ser una pérdida de seguridad jurídica; por el otro, el costo de optar por la seguridad jurídica reprimiendo a la desobediencia civil puede ser perder la legitimidad. Ambas pérdidas ponen a prueba el Estado democrático por razones distintas. La pérdida de legitimidad, si el Estado quiere sobrevivir, conduce al autoritarismo; la falta de seguridad jurídica provoca la inefectividad del orden político dando paso al caos y a la anarquía.

Para que se recupere el equilibrio, es necesario que el sistema político sea capaz de incorporar la desobediencia civil en los procesos institucionales, pues de lo contrario resultaría un serio desorden que acabaría por minar la efectividad del orden político. Existen ciertos límites dentro de los cuales la desobediencia civil puede, en efecto, ser incorporada. Especialmente, el hecho de que diversos grupos recurran a la desobediencia civil en forma simultánea puede hacer que la situación se vuelva incontrolable.

${ }^{23}$ John Rawis, Teoría de la justicia, op, cit, p. 49. 
Entonces, la pérdida parcial de la legitimidad de la que parte la desobediencia civil puede convertirse en pérdida total de legimitidad dado que además se mina la seguridad jurídica. En estos casos, cuando la desobediencia civil se generaliza y no logra encauzarse por las vías institucionales, se convierte en un preludio de movimientos radicales. Por esta razón la eficacia de la desobediencia civil declina más allá de cierto punto, y quienes la contemplan deben considerar estos límites.

Cuando la desobediencia civil se logra incorporar a los procesos institucionales, constituye un recurso estabilizador del sistema político porque vigila su legitimidad, revisa las desviaciones y promueve la realización de correcciones y cambios pacíficos. En consecuencia, la desobediencia civil utilizada con las debidas reservas y en forma reflexiva, ayuda a mantener y reforzar tanto la legitimidad como la efectividad de las instituciones democráticas adaptándolas a las circunstancias cambiantes.

El que se obtengan resultados tan divergentes hace que sea fundamental explorar cuáles son esas reservas y límites.

\section{Límites de tolerancia de la desobediencia civil}

Los límites dentro de los que la desobediencia civil puede ser efectivamente incorporada en el Estado democrático dependen, en gran medida, del tipo específico de sistema político del que se trate y de su mayor o menor capacidad de respuesta. Aquí se propone una enumeración bastante esquemática aplicable al Estado democrático considerado en abstracto. Por ello, se debe adaptar y matizar según las situaciones concretas que se presenten en un sistema político determinado.

La desobediencia civil debe limitarse a una reivindicación claramente especificada. Resulta razonable recurrira a la desobediencia civil sólo cuando hay una injusticia bien determinada; es decir, como una forma de protesta en contra de una norma jurídica, política gubernamental, sentencia judicial o proceso decisional que se considere incompatible con los principios políticos que subyacen en las instituciones democráticas. Es necesario además que la protesta esté dirigida en contra de actos de autoridad, ya sea ejecutiva, 
legislativa o judicial o en contra de actos de organismos subsidiarios del Estado cuyas decisiones están apoyadas por la fuerza coercitiva del poder político. Es decir, la desobediencia civil debe precisamente estar dirigida en contra de una injusticia, ya sea directamente cometida por el poder político o indirectamente, esto es, cuando esté apoyada con su fuerza pública, y no en contra de actos de particulares.

Es necesario además, que la desobediencia civil no se utilice como una estrategia más para competir por el poder político. Ésta se caracteriza esencialmente por ser una organización no institucionalizada de ciudadanos, unidos tan sólo por una fuerte identidad moral colectiva, que busca cambiar leyes o políticas consideradas ilegítimas o promover valores en el proceso de formación del consenso, cuando los canales ordinarios están cerrados. En consecuencia, sus reivindicaciones no están en competencia en el mercado político. En esta medida, un grupo de desobediencia civil se diferencia de los partidos políticos porque no busca atraer votos en el mercado político y tampoco competir por el poder. De otra forma, la desobediencia civil, como estrategia de lucha esencialmente moral, se desvirtúa y pierde su razón de ser. Cabe aclarar que esta reflexión se sitúa en el contexto de un Estado democrático en el que los procesos electorales se siguen con apego a la ley, lo que abre vías eficientes para el intercambio del poder político sin derramamiento de sangre. Esto, según Karl Popper, distingue esencialmente a un gobierno democrático de uno no democrático. Por esta razón, los Estados que carecen de este mínimo contenido de democracia, están más cercanos al modelo de Estados autoritarios, a pesar de que se sustentan en una Constitución democrática. En ellos la desobediencia civil adquiere matices particulares, por lo que no es de extrañar que se utilice como una estrategia más, alternativa a la violencia, para competir por el poder político cuando los canales legales están cerrados. Aquí, no se puede hablar propiamente de desobediencia civil, especialmente si se le utiliza por un partido político. Por un lado, no existe una reivindicación moral, sino que ésta se identifica con la ideología del partido. Por lo mismo, no apela a la conciencia de la sociedad, sino a ganar votos. 
La tercera condición es que la desobediencia civil debe fundamentarse en los principios político-morales que regulan la Constitución y las instituciones sociales y no apelar a principios de moralidad personal o a doctrinas religiosas, aunque éstas pueden coincidir. Con la desobediencia civil una minoría intenta persuadir a los poderes públicos a que cambien ciertas leyes, políticas o procesos decisionales. Para ello apela a la sensibilidad moral y conciencia política del resto de la sociedad, de cuyo apoyo depende su efectividad. Es decir, la desobediencia civil está dirigida a desencadenar conductas de terceros para producir un nuevo proceso de formación de la voluntad política, por lo que trasciende, a dieferencia de la objeción de conciencia, de la esfera individual a la esfera pública colectiva. Se utiliza, no para trazar fronteras para que ningún acto pueda transgredir las normas de la conciencia, sino para promover cambios sociales. En esta medida, debe fundamentarse en los principios político-morales en los que se sustenta el orden político y la sociedad en general, pues de lo contrario se estaría imponiendo autoritariamente la conciencia individual sobre la de los demás.

Con frecuencia no existe un consenso respecto de la manera como los principios políticos fundamentales deben ser interpretados y en qué medida se aplican a un problema social determinado.

Hay casos respecto de los que es razonable esperar un consenso porque la violación de dichos principios es obvia, especialmente cuando se violan en forma flagrante los derechos humanos, como por ejemplo; cuando hay ciertas minorías a las que se niega el derecho a votar, a participar en el gobierno, a practicar ciertas creencias religiosas, a poseer propiedad o a trasladarse. En estos casos extremos la desobediencia civil, que se puede decir está motivada en razones de justicia, se justifica aun cuando el proceso democrático funcione adecuadamente.

Sin embargo, hay otros casos respecto de los que a menudo existe un amplio campo de opiniones conflictivas acerca de si se satisfacen o no dichos principios, especialmente se trata de políticas gubernamentales como por ejemplo, la militar, la ecológica o la económica. Si el proceso democrático funciona adecuadamente en cuanto a la libre discusión de las ideas, esta última forma de desobediencia civil, que se puede decir está motivada en razones político-morales, difícilmente se justifica. Se puede recurrir a ella cuando el sistema 
de decisión colectiva se desvía de hecho de sus pretensiones formales y los canales de crítica y disenso están cerrados. Por ejemplo, cuando no hay espacio para una discusión crítica de una política gubernamental porque es decidida por un reducido grupo, fuera del proceso democrático, y la información se controla y suministra a la población en forma parcial y distorsionada, tal como ocurrió durante el movimiento de desobediencia civil en contra de la política nuclear británica, según lo explica Bertrand Russell. ${ }^{24}$ En estos casos la desobediencia civil es congruente con los ideales democráticos, a pesar de que no exista un consenso social respecto de qué tanto la política en cuestión satisface los principios y valores sociales fundamentales. Se acepta precisamente porque suscita un nuevo debate, a la luz de éstos principios, respecto de la política en cuestión. Así, no hay un criterio para decidir si dicha política es moralmente aceptable, lo cual no representa necesariamente una objeción, sino que la misma discusión pública constituye una condición necesaria para el avance social.

Otro requisito es que la desobediencia civil debe ser el último recurso. Esto no significa que los medios jurídicos y políticos disponibles deban de ser agotados totalmente. Se requiere que hayan sido utilizados al máximo hasta que sea evidente que a través de ellos no se logrará nada. Así, por ejemplo, si las acciones que se lleven a cabo, como escritos, manifestaciones legales, cabildeo e interposición de demandas judiciales en caso de ser procedentes, demuestran que todo intento por las vias institucionales será estéril, sólo queda el recurso de la desobediencia civil. El momento en el que se llega al grado de agotamiento de estos recursos debe ser precisado según el caso particular que se presente y la capacidad de respuesta del sistema político en cuestión. Si los procesos judiciales son excesivamente lentos y costosos, los medios de comunicación dan acceso sólo a información privilegiada y las autoridades se muestran inaccesibles, el grado de agotamiento será alcanzado más rápidamente. Se puede también pensar en dos tipos de casos ideales

${ }^{24}$ Véase Peter Singer, Democracy and Disobedience, Oxford University Press; Oxford, 1973. Dicho autor analiza, citando a Bertand Russell, las razones del movimiento de desobediencia que se siguió en contra de la política nuclear quedó fuera del proceso democrático en la medida que se cerraron los canales para la discusión racional de los asuntos nucleares y la influencia de ésta en la política. 
extremos en los que no exista el deber de utilizar en primera instancia los medios isntitucionales disponibles. El primero, casos en los que se violan derechos fundamentales que dejen totalmente sin defensa a una minoría débil, como por ejemplo, la promulgación de una ley que la despoje de sus propiedades. El segundo, casos en los que exista el peligro real, de que el daño ocurra antes de que dichos medios se resuelvan, como por ejemplo, la promulgación de una ley por la que se permita la pena de muerte por motivos políticos y la disposición manifiesta de la autoridad a ejecutarla.

La última condición es que la desobiediencia civil no sea utilizada como una forma de coerción sino de persuasión no violenta. La coerción se caracteriza por la intolerancia. Está dirigida a la obtención de una conducta, por parte de otros, mediante la anulación de su capacidad de decisión libre. Esto se realiza normalmente mediante la amenaza de ocasionar daños mayores, aun cuando no medie el uso de la fuerza física. En consecuencia, excluye toda posibilidad de negociación. La persuasión, en cambio, se funda en el hecho de que se puede estar equivocado y en que la percepción que se tenga de una situación, aún en el análisis más cuidadoso, siempre será parcial. Se dirige a influenciar la conducta de los otros, pero no a través de la intimidación, sino despertando su conciencia moral y racional. Para ello es necesario mantener un espíritu de apertura al diálogo y a la negociación. La desobediencia civil busca precisamente impulsar un nuevo proceso de formación racional de la voluntad política. En esta medida debe, necesariamente, partir de la humildad intelectual. Por ello los desobedientes civiles deben construir sus puntos de vista sin sobrevalorar sus intereses y visiones personales, aun cuando puedan tener razón. De lo contrario, difícilmente se podrán incorporar sus demandas a los procesos institucionales y la eficacia de esta forma de protesta se veră minada.

Esta discusión acerca de los límites de tolerancia de la desobediencia civil en un Estado democrático puede conducir a dos líneas de reflexión.

La primera es de índole positiva, es decir, la especificación de las condiciones para la efectividad de los movimientos de desobediencia civil. Esto es, las condiciones por las que dichos movimientos pueden ser en efecto incorporados en los procesos institucionales de un Estado democrático, y así desempeñar el papel de abrir el 
sistema político, promover cambios y reivindicaciones pacíficas y vigilar su legitimidad. Cuando la desobediencia civil sobrepasa estos límites de tolerancia, es de esperarse que fracase como movimiento social.

La segunda es de índole normativa, es decir, establece un marco de valores político-morales para llevar a cabo una desobediencia civil justificada en la democracia. Así, esta segunda línea de reflexión puede dar pautas para, por un lado, quienes contemplan la desobediencia civil, y por el otro, las autoridades, especialmente los jueces, encargadas de resolverla y juzgarla. Si la desobediencia civil se comete dentro de los límites de tolerancia, puede ser claramente deferenciada de actos destructivos del sistema político, como de los delitos comunes o de los delitos políticos, y así considerarse como un acto antijurídico, pero moralmente justificado, que en consecuencia no debe ser perseguido penalmente. 